\title{
The Relationship Between Tolerance For Ambiguity And Students' Propensity To Cheat On A College Exam
}

James H. Thompson (E-mail: jht@okcu.edu), Oklahoma City University Jane S. Austin (E-mail: jaustin@okcu.ecu), Oklahoma City University Bruce A. Walters (E-mail: bwalters@latech.edu), Louisiana Tech University

\begin{abstract}
Businesses in the United States are being ravaged internally for a total of up to $\$ 400$ billion yearly by white-collar crime (Martin, 1998). Fraud, the culprit, is defined as, "deceit; trickery; cheating" (Webster's New World dictionary, 1978). This phenomenon knows no bounds, has no feelings, respects no one; and its perpetrators are described as the "greatest threat to businesses of all sizes" by Mark Simmons, a New York-based auditor with 20 years' experience of fighting fraud (Applegate, 1998). This exploratory study is aimed at gaining a greater understanding of the psychological consistency of these perpetrators, who remain a constant threat to business education.
\end{abstract}

\section{Fraud and Cheating}

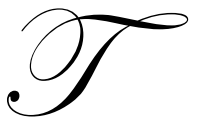

hree elements must be present in order that fraud may occur: opportunity, need, and rationalization (Zeune, 2001). Internal controls (Trumfio, 1995), well-written job descriptions as well as duties (Applegate, 1998), codes of conduct, zero tolerance policies (Cowan, 2000), fidelity bonds (Baier, 1994), SAS 82 audit requirements (Zeune, 1997), and a new International Standard on Auditing's requirement that an auditor consider fraud and error in a financial statement audit (Brune, 2001) are all aimed toward minimizing, controlling, or discovering fraud. However, by the time these go into effect, the main error has occurred; the wrong person has been hired. Pre-employment screening, by the use of background checks or personality tests, should be a first step in fraud prevention (Martin, 1998).

Fraud tends to be driven by one of two factors, situational need, or personality need. Situational need can be either direct or indirect. Direct need occurs when one steals for cash due to addictions such as drugs, alcohol, gambling, affairs (Zeune, 2001), extravagant lifestyle (Baier, 1994; and Trumfio, 1995), or to fund the bills for a family illness (Applegate, 1998). Indirect need is triggered due to a significant upcoming event, and the books are altered in order to receive a loan, go public, snag a large customer, etc. (Zeune, 2001).

Personality fulfillment encompasses another fraud catalyst. Fraud may be perpetuated by bored employees who seek novelty, curious employees who attempt to circumvent systems to steal information, and risk-taking employees who may steal for the sheer fun of doing so. Many of the perpetrators fit neatly into normal society. A typical perpetrator of bank fraud might be described as follows: "they earn an adequate salary, hold positions of trust within the bank (many are longtime employees), and are active in religious and civic activities. They are also bright, creative, and energetic; outwardly self-confident and willing to accept responsibility and challenge; adventurous; and highly motivated at work" (Thornhill, 1990).

Rationalization of the fraud act is described by Zeune (2001) as the process of the employee mentally fitting and adjusting this act into his or her own personal moral code. 
For instance, the money taken may be viewed as a loan, meant to be repaid, rather than a theft (Trumfio, 1995), or as money "due" the employee because he or she feels underpaid, angry with management, or "wronged" according to David Ramirez, president of a Miami-based consulting firm (Applegate, 1998).

Cheating has been problematic in both college and high school (Minkel and McCaffrey, 2001)("Prime Numbers," 2001). In a study of medical students, $2 \%$ stated they had copied, or would consider copying answers in a degree examination (Rennie and Crosby, 2001). Arguably, a much greater percentage probably have cheated. Factors that tend to curb cheating include teachers' caring about the issue, developing codes of ethics and honor codes (Minkel and McCaffrey, 2001), and using a computer program that detects plagiarism (Gilgoff, 2001). These techniques help remove some of the opportunities and motivations for cheating.

Need incites cheating as well as fraud. Situational triggers include parental pressure for good grades, exceptional rewards from teachers for excellent grades, lack of confidence in the student's own abilities (Tutelian, 2001), and interference from sports and other activities (Tutelian, 2001; and "The Young," 2001). Rationalization is usually not difficult for the student. Many values are embedded within students before they are tempted to cheat (Glick, 2001; "The Young," 2001). Some students perceive the course to be insignificant ("The Young," 2001), are lazy, or attempt to cheat to see if they think that they can "get away with it" (Tutelian, 2001).

\section{Tolerance for Ambiguity}

The propensity to rationalize for both the fraud perpetrator and the cheater is increased when one can tolerate ambiguity well. Situations in which fraud or cheating is likely to occur often involve an ambiguous situation (i.e., a situation not able to be satisfactorily categorized or structured by a person due to insufficient cues). These situations may be new, complex, or contradictory. Those tolerant of ambiguity tend to interpret ambiguous situations as something to be desired (Budner, 1962). Tolerance for ambiguity has been shown to moderate relationships between role ambiguity and job-related tension in employees (Lysonski and Durvasula, 1990), role ambiguity and indices of strain (Frone, 1990), and role ambiguity and feedback-seeking behavior (Ashford and Cummings, 1985). The personality of the fraudulent individual has been studied previously (Collins and Schmidt, 1993; and Mikulay and Goffin, 1998), but tolerance for ambiguity has not been studied in conjunction with such individuals.

\section{Exploratory Questions}

The foregoing discussion leads to several research questions considered worthy of exploration. First, because those who cheat may be operating within ambiguous situations, are they likely to differ in tolerance for ambiguity from those who do not cheat? Additionally, because those who are intolerant of ambiguity are more likely to be characterized by the acceptance of attitude statements that represent a rigid black-white view of life (Frenkel-Brunswik, 1948), does this suggest that tolerance for ambiguity may differ between those who feel that cheating is morally wrong and those who do not?

Additionally, are controls over cheating an important consideration — for those who have not cheated, is there a difference in tolerance for ambiguity between those who have not cheated based on various justifications (see Appendix A)? Also, those who are highly tolerant of ambiguity may have cheated several times during college. For those who have cheated, do they cheat more often when stress increases, and are they more intolerant of ambiguity than those who cheat when stress is less serious? Are those who are low in tolerance for ambiguity likely to seek feedback more often than those who are more tolerant (Ashford and Cummings, 1985)? Are those who are caught cheating likely caught when trying to seek feedback, i.e., viewing to see if the professor is noticing their behavior?

\section{Limitations}

The validity, as well as the generalizability, of this, as well as any other research study may be affected by factors contained in such study. Limitations inherent in this study will now be discussed. First is the sample utilized in the study. The sample was a convenience sample drawn from 2 graduate business courses in a Midwestern United States 
university. These courses were chosen because they are required of all graduate Masters of Business Administration students, and such students should be entering the field of business shortly. The data obtained was cross-sectional and did not explain whether such students change in tolerance of ambiguity levels over time.

\section{Research Design}

This study used an ex post facto experimental design. In this design, there is no experimental manipulation, nor is there random assignment of subjects.

\section{Variable}

Cheating behavior was one variable chosen for this research. This variable was based upon the subject's response to question six of the questionnaire (had he/she cheated on a college exam; see Appendix A for a copy of the questionnaire).

Morality of cheating was a variable assessed by the response to question seven of the questionnaire. This question was utilized to determine whether those who had cheated did so with the knowledge that such behavior was morally wrong, rather than with the lack of such knowledge due to differences in cultural values and behavior.

Cheating /noncheating justifications were variables dependent upon subjects' responses to questions eight (noncheating justifications from noncheaters) and ten (cheating justifications from cheaters). The reasons for cheating / noncheating given in the questionnaire were utilized in an attempt to explore the rationales of both cheaters and noncheaters for their behavior.

Number of college exams cheated on was a variable used to assess the frequency of cheating behavior, and number of times caught cheating in college was a variable used to determine the frequency of times such behavior was circumvented.

Tolerance for ambiguity was another variable selected for study (see prior definition by Budner, 1962). Ambiguous situations are those that cannot be satisfactorily categorized or structured by a person due to insufficient cues. These situations may be new, complex, or contradictory. Reactions to stimuli which indicate "repression and denial ... anxiety and discomfort ... destructive or reconstructive behavior . . or avoidance behavior" (Budner, 1962, p. 30) indicates that a person is threatened (Budner, 1962). Tolerance for ambiguity was measured utilizing the 20 -item ambiguity tolerance test (AT-20) developed by A.P. MacDonald, Jr. (1970). This scale includes 16 items from the Rydell-Rosen (1966) tolerance for ambiguity scale, and adds four more items. According to MacDonald, Jr. (1970), this test possesses good measurement characteristics; it demonstrated a coefficient of internal consistency of $0.86(\mathrm{r}=.73$ when using the more conservative Kuder-Richardson Formula 20) in a sample of 74 female undergraduate students at Cornell University. Later, when administered to 789 undergraduate students at Ithaca College, an r of 0.63 (K-R 20) resulted. Retest reliability (for a group of 24 male undergraduate students) has been estimated at 0.63 . Correlations have been found between tolerance for ambiguity using this test, and performance in ambiguous tasks (scrambled words test). This test (AT-20) has exhibited a relationship to dogmatism, rigidity, and church attendance, and is free from social desirability response bias. In this study, a "1," while incorrect responses were scored with a "0" scored correct responses by each student for a High Tolerance for Ambiguity. Each student's total responses were then totaled, and that comprised the total Tolerance for Ambiguity score for that particular student.

\section{Method}

Sixty-seven college students from two graduate business courses at a university in Midwestern United States participated (sixty-five usable questionnaires) as subjects for the study prior to the inception of testing in the fall of 2001. 


\section{Results}

\section{Cheating Behavior}

Six subjects responded that they had cheated on a college exam. Seven additional subjects who responded "no" to the initial cheating question (number 6) indirectly admitted they had, in fact, cheated on exams, by their response to the number of exams they had cheated on in their response to question 9 (see appendix). A two-tailed Wilcoxon Rank Sum test indicates that the tolerance for ambiguity levels for the initial six responders were not significantly different than those of the seven "confessed" cheaters ( $p>$.77). Therefore, the two groups were combined into one group of thirteen "examination cheater" subjects.

For both cheaters and noncheaters, there were more than twice as many males as females. See Table 1 for the Sex and Age Distribution of the cheater / noncheater groups and Table 2 for the Ethnic Distribution. From the standpoint of ethnicity, oriental students comprised most of the sample groups. Perhaps a different gender or ethnic mix might have resulted in different findings than those described below. Figures 1 and 2 present graphs of the tolerance for ambiguity of both cheaters and noncheaters. With regard to tolerance for ambiguity, there was a significant difference between medians found between cheaters and noncheaters $(p>.09)$. See Figure 2 for a graph of the distribution.

${ }^{1}$ A Wilcoxon Rank Sum two-tailed test found no difference in tolerance for ambiguity levels between cheaters and noncheaters $(\mathrm{p}>.17)$.

\section{Moral Persuasion And Cheating Behavior}

A Wilcoxon Rank-Sum test indicated there was no difference in tolerance for ambiguity levels between those who felt cheating was morally wrong and those who did not ( $p>.31$ ). Evidently moral persuasion does not always affect cheating behavior; the two subjects who indicated cheating was not morally wrong indicated they did not cheat, and 13 of the 62 subjects who responded that cheating was morally wrong, actually cheated. These results may indicate the possibility that subjects are operating from various levels of moral reasoning. According to Kohlberg (1969), people may address moral dilemmas at any of six stages of moral reasoning. The stages accompany cognitive skill requirements ranging from lower-level skills to higher-level skills. Examples include recognition of the likelihood of punishment (lower-level) and an understanding of universal ethical principles (higher-level). In the present situation, subjects who responded that cheating was morally wrong, but actually cheated, may perhaps be operating at a "pre-conventional level" (Elm \& Nichols, 1994) of moral development. In this case, primary concerns are described by questions such as "Will I get caught" and "What will I get out of it?"

A Kruskal-Wallis Test was utilized to test for the relationship between tolerance for ambiguity level and the 3 reasons cited in the questionnaire for not cheating. No difference in tolerance for ambiguity level was detected for any of the three reasons $(\mathrm{p}>$.64). However, several interesting observations were discovered. The morality of cheating was the primary reason given for not cheating, but the monitoring, and /or the anticipated monitoring of the exam by the professor accounted for 16 percent of the reasons given for not cheating. (See Table 4.) Again, an analysis of subjects' stages of moral reasoning might be revealing here. If the primary concern is getting caught, this might suggest lower levels of moral judgment. If, on the other hand, subjects are operating from a "conventional level" of moral reasoning, this might reflect a law and order orientation or the desire to be "good" or "nice." More rarely, individuals may exhibit a "postconventional level" of moral reasoning, where the primary concerns are societal standards through consensus or universal ethical principles (Elm \& Nichols, 1994; Kohlberg, 1969).

It was expected that those who cheated due to severe situational stress had not developed a threshold for cheating and therefore would cheat less than those who did so when stress was less severe. A Wilcoxon Rank-Sum test was administered to test the responses to question 9. Table 5 shows the frequency distribution of the responses. No significant difference was found between those who cheated due to lowering of grade-point averages (no other severe consequences) and those who cheated due to more severe consequences (flunking the course, being put on academic probation, or being kicked out of school because of the resulting low grade point average $(\mathrm{p}>.56)$ 
Based on previous conjecture, one might suspect that there would be a negative association between the tolerance for ambiguity score and the number of times a person is caught cheating. Only 2 of the 13 subjects reported being caught (there were 2 missing responses); those caught indicated being caught either one or two times. The association between tolerance for ambiguity level and number of times cheaters were discovered cheating was extremely small and negative $(r=-.17)$, and it was not statistically significant $(\mathrm{p}>.62)$. There was no significantly significant relationship between tolerance for ambiguity level and the number of times cheaters were caught cheating.

\section{Conclusion}

Tolerance for ambiguity appeared to differ between cheaters and non-cheaters. Perhaps it is indeed the case that individuals with higher tolerance for ambiguity are more accommodating of ambiguous situations and perhaps can rationalize a variety of behaviors. An interesting extension would be to compare these groups based on level of moral reasoning, perhaps using Weber's (1991) adaptation of Kohlberg's Moral Judgment Interview (MJI).

Interestingly, moral persuasion did not always affect cheating behavior; the two subjects who indicated cheating was not morally wrong apparently did not cheat; yet 13 of the 62 subjects who responded that cheating was morally wrong actually cheated. No difference in tolerance for ambiguity level was found between tolerance for ambiguity level and 3 reasons given for not cheating $(p>.64)$. Although the morality of cheating was the primary reason given for not cheating, the monitoring, and/or the anticipated monitoring of the exam by the professor accounted for 16 percent of the reasons cited for not cheating. Tolerance for ambiguity level did not significantly affect the number of times a student cheats in college $(r=.31)(\mathrm{p}>.39)$. No significant difference was found between those who cheated due to lowering of grade-point averages (no other severe consequences) and those who cheated due to more severe consequences (flunking the course, being put on academic probation, or being kicked out of school because of the resulting low grade point average $(\mathrm{p}>.56)$. The association between tolerance for ambiguity level and number of times cheaters were caught cheating was extremely small and negative $(r=-.17)$, and was not statistically significant $(p>.62)$.

Future researchers might consider repeating this study using a larger sample of graduate students. The additional degrees of freedom should aid in uncovering relationships that may be hidden due to small sample size. Moreover, other college majors should be explored regarding the above relationships. An exploration of respondents' level of moral judgments could be illuminating for several reasons. For instance, in the U.S., business students have been shown to be less ethical than other students (Useem, 1989; Zinkhan, Bisei, \& Saxton, 1989). Are there links among tolerance for ambiguity, level of moral judgment, choice of college major, and country of origin? The use of the Weber's (1991) MJI or a similar instrument could help in uncovering various justifications for moral responses in the context of the aforementioned control variables, bringing us closer to an understanding of important covariates of psychological traits such as tolerance for ambiguity.

\section{References}

1. Applegate, J. (1998). "Employee theft small business' greatest problem", San Diego Business Journal. 19, 33-35.

2. Ashford, S., and Cummings, L. (1985). "Proactive feedback seeking: The instrumental use of the information environment", Journal of Occupational Psychology, 58, 67-97.

3. Baier, M. J. (1994). Companies that fall from within. 62, 46-50.

4. Brune, C. (2001). "New guidance directs auditors", Internal Auditor. 58, 13-15.

5. Budner, S. (1962). "Intolerance of ambiguity as a personality variable", Journal of Personality, 30, 29-50.

6. Collins. J. M., and Schmidt, F. L. (1993). "Personality, integrity, and white collar crime: a construct validity study", Personnel Psychology. 46, 295-311.

7. Cowan, N. (2000). "Company-wide fraud offensive",. Internal Auditor. 57, 88.

8. Frenkel-Brunswik, E. (1948). "Intolerance of ambiguity as an emotional perceptual personality variable", Journal of Personality, 18, 108-143.

9. Frone, M. (1990). "Intolerance of ambiguity as a moderator of the occupational role stress-strain relationship", Journal of Organizational Behavior, 11, 309-320. 
10. Gilgoff, D. (2001). "Click on honorable college student”, U.S. News \& World Report. 130, 51-53.

11. Glick, S. M. (2001). "Cheating at medical school”, British Medical Journal. 322, 250-51.

12. Gonick, L., and Smith, W. (1993). The Cartoon Guide to Statistics. New York, N.Y.:Harper Perennial.

13. Guralnik, D. B. (Ed.). (1978). Webster's New World Dictionary of the American Language. New York, N.Y.:Avenel Books.

14. Lysonski, S., and Durvasula, S. (1990). "Effects of moderating variables on product managers' behavior: A reexamination", Psychological Reports, 67, 687-690.

15. MacDonald, A. (1970). "Revised scale for ambiguity tolerance: Reliability and validity", Psychological Reports, 26, 791-798.

16. Martin, J. (1998). "An HR guide to white collar crime", HR Focus, 75, 1-3.

17. Mikulay, S. M., and Goffin, R. D. (1998). "Measuring and predicting counterproductivity in the laboratory using integrity and personality testing”, Educational \& Psychological Measurement. 58, 768-772.

18. Minkel, W., and McCaffrey, M. (2001). "Kids and cheating, 2001", School Library Journal. 47, $30-31$.

19. Prime Numbers. (2001, May 11). Chronicle of Higher Education. 47, 35-39.

20. Rennie, S. C., and Crosby, J. R. (2001). “Are 'Tomorrow's doctors' honest? Questionnaire study exploring medical students' attitudes and reported behavior on academic misconduct”, British Medical Journal. 322, 274-275.

21. Rydell, S. T. (1966). "Tolerance of ambiguity and semantic differential ratings",. Psychological Reports, 19, 1303-1312.

22. Rydell, S. T., and Rosen, E. (1966). "Measurement and some correlates of need-cognition", Psychological Reports, 19,139-165.

23. Thornhill, W. (1990). "The high cost of bank fraud", Bankers Magazine. 173, $27-31$.

24. Trumfio, G. (1995). “Are your salespeople stealing your profits?”, Sales \& Marketing Management. 147, 33-34.

25. Tutelian, L. (2001). "The new cheating epidemic", Family Life. (Sept.), 76-79.

26. Young and the Virtueless. (2001). U.S. News \& World Report. 130, 51-53.

27. Zeune, G. D. (2001). “Are you teaching your employees to steal?”, Business Credit. 103, 16--21.

28. Zeune, G. D. (1997). "Bloodhounds not watchdogs", Business Credit. 99, 30-32.

Table 1: Sex And Age Distribution Of Noncheaters / Cheaters

\begin{tabular}{lccc}
\hline Response to Cheating Question & 20--29 & 30--39 & Total \\
\hline Noncheaters & 14 & 2 & 16 \\
$\quad$ Female & 28 & 8 & 36 \\
$\quad$ Male & 1 & 0 & 2 \\
Cheaters & 8 & 2 & 11 \\
$\quad$ Female $^{\mathrm{a}}$ & & & \\
Male $^{\mathrm{b}}$ & & & \\
${ }^{\mathrm{a}}$ There was 1 response missing in this category. & &
\end{tabular}

Table 2: Ethnic Distribution Of Noncheaters / Cheaters

\begin{tabular}{lcccccc}
\hline $\begin{array}{l}\text { Response to } \\
\text { Cheating Question }\end{array}$ & Caucasian & $\begin{array}{c}\text { Afro- } \\
\text { American }\end{array}$ & $\begin{array}{c}\text { American } \\
\text { Indian }\end{array}$ & Hispanic & Oriental & Other \\
\hline Noncheaters $^{\mathrm{a}}$ & 3 & 1 & 1 & 4 & 26 & 14 \\
Cheaters $^{\mathrm{b}}$ & 2 & 1 & 0 & 1 & 6 & 2 \\
\hline
\end{tabular}

${ }^{\mathrm{a}}$ There were 3 missing responses in this category.

${ }^{\mathrm{b}}$ There was 1 missing response in this category. 
Table 3: Morality Of Cheating Frequency Distribution

\begin{tabular}{lc}
\hline Is Cheating Morally Wrong? & Frequency \\
\hline Yes & 62 \\
No & $\frac{2}{65}$ \\
Total $^{\mathrm{a}}$ & \\
${ }^{\mathrm{a}}$ There is 1 missing response. &
\end{tabular}

Table 4: Frequency Distribution Of Reasons For Not Cheating

\begin{tabular}{|c|c|}
\hline Reason for Not Cheating & Frequency \\
\hline Cheating is Morally Wrong & 43 \\
\hline Aware of Monitoring & 4 \\
\hline Unaware of, But Anticipated the & 4 \\
\hline Use of Monitoring & \\
\hline Total $^{\mathrm{a}}$ & 52 \\
\hline
\end{tabular}

Table 5: Frequency Distribution Of Reasons For Cheating

\begin{tabular}{lc}
\hline Reason for Cheating & Frequency \\
\hline $\begin{array}{l}\text { Afraid Grade Point Average Would Go Down } \\
\text { (no other severe consequences) }\end{array}$ & 9 \\
$\begin{array}{l}\text { Afraid of Flunking the Course } \\
\text { Or Other Severe Consequences } \\
\text { Total }^{\text {a }}\end{array}$ & $\underline{2}$ \\
${ }^{\text {aThere were 2 missing responses. }}$ & 11 \\
\end{tabular}


Figure 1: Tolerance For Ambiguity Level Of Subjects

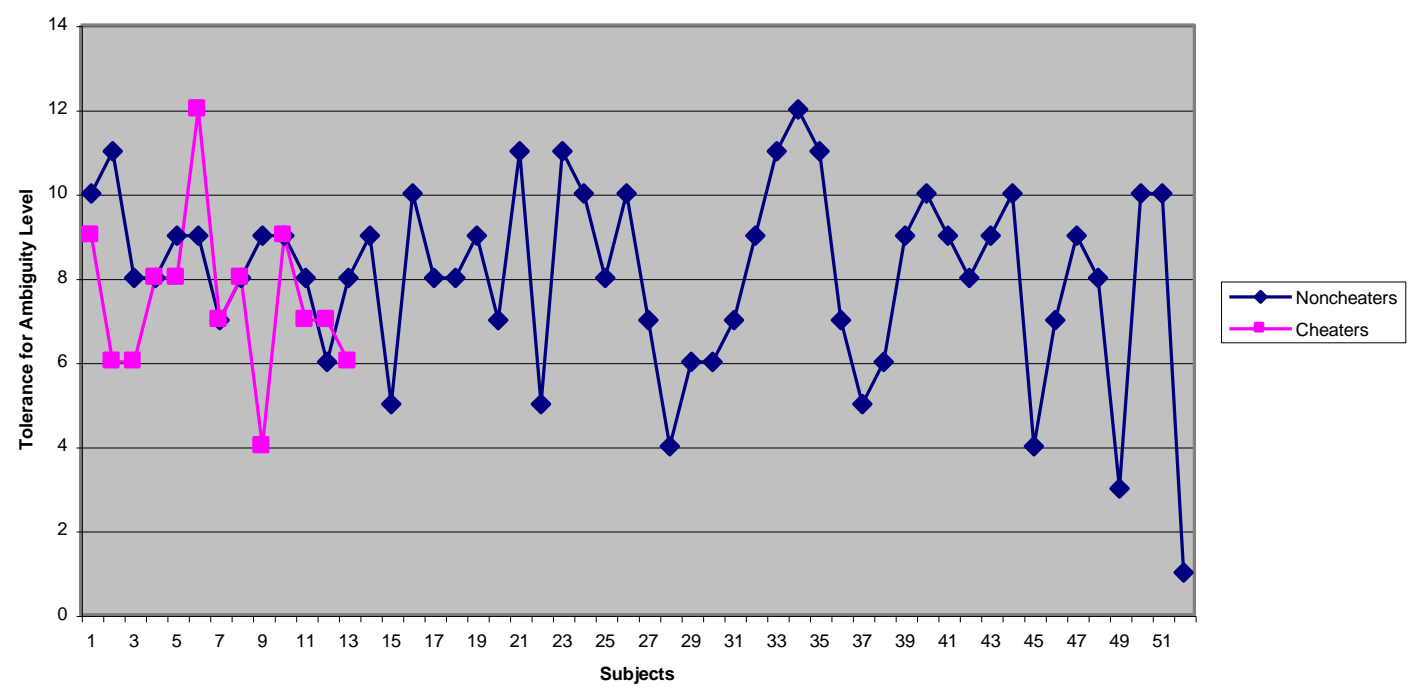

Figure 2: Tolerance For Ambiguity Level And The Number Of Times Cheated In College

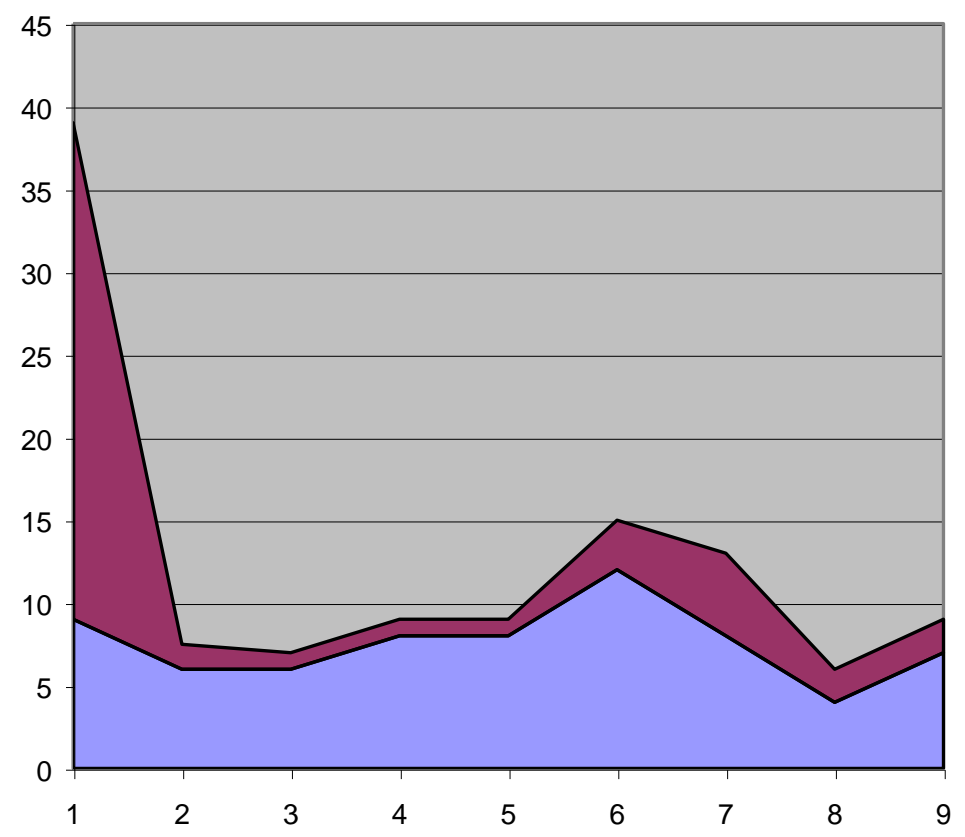

Number of Times Cheated in College

Tolerance for Ambiguity Level 


\section{Appendix A}

Please complete the following form. Thank you in advance for your time.

$\underline{\text { Personal Information }}$

1. Sex (Mark the correct response with an X):

Male

Female

2. Age: __ Years

3. Which term best describes you (Mark the correct response with an X):

4. Years of College:

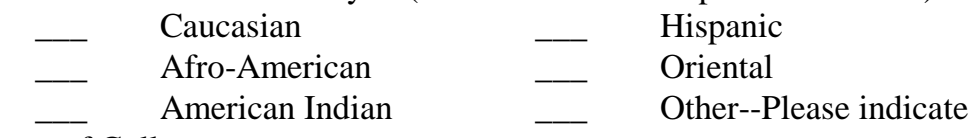
Caucasian
Oriental

5. Grade Point Average (work for the degree you are now working toward)

$(4.00=\mathrm{A})$

6. Have you ever cheated on a college exam (cheating is described as using any other information source during the exam other than that which is allowed by the professor, such as crib sheets, someone else's test paper, etc.):

$$
\text { Yes }
$$

7. Do you feel that cheating is morally wrong?:

$$
\text { Yes }
$$$$
\text { No }
$$

8. If you did not cheat on an exam, which of the following best describes the reason why you did not cheat (select only 1 response):

Cheating is morally wrong.

_ I was aware that the professor was monitoring the exam to catch cheating.

_ I I was not aware if the professor was monitoring the exam to catch cheating, but I was afraid that I would be caught.

9. If you did cheat, approximately how many exams have you cheated on during college:

10. If you did cheat, which of the following best describes the reason why you cheated:

I was afraid that my grade point average would go down (but the test would not cause me to flunk the course, put me on academic probation, or get me kicked out of school because of the resulting low grade point average.

_ I was afraid of flunking the course, being put on academic probation, or being kicked out of school because of the resulting low grade point average.

11. If you did cheat, how many times were you caught cheating on college exams:

Please do not spend too much time on the following items. There are no right or wrong answers and therefore your first response is important. Mark $\mathrm{T}$ for true and $\mathrm{F}$ for false. Be sure to answer every question.

1. A problem has little attraction for me if I don't think it has a solution.

2. I am just a little uncomfortable with people unless I feel that I can understand their behavior.

3. There's a right way and a wrong way to do almost everything.

4. I would rather bet 1 to 6 on a long shot than 3 to 1 on a probable winner.

5. The way to understand complex problems is to be concerned with their larger aspects instead of breaking them into smaller pieces.

6. I get pretty anxious when I'm in a social situation over which I have no control.

7. Practically every problem has a solution.

8. It bothers me when I am unable to follow another person's train of thought.

9. I have always felt that there is a clear difference between right and wrong.

10. It bothers me when I don't know how other people react to me.

11. Nothing gets accomplished in this world unless you stick to some basic rules. 
12. If I were a doctor, I would prefer the uncertainties of a psychiatrist to the clear and definite work of someone like a surgeon or X-ray specialist.

13. Vague and impressionistic pictures really have little appeal for me.

14. If I were a scientist, it would bother me that my work would never be completed (because science will always make new discoveries).

15. Before an examination, I feel much less anxious if I know how many questions there will be.

16. The best part of working a jigsaw puzzle is putting in that last piece.

17. Sometimes I rather enjoy going against the rules and doing things I'm not supposed to do.

18. I don't like to work on a problem unless there is a possibility of coming out with a clear-cut and unambiguous answer.

19. I like to fool around with new ideas, even if they turn out later to be a total waste of time.

20. Perfect balance is the essence of all good composition.

Notes 